\title{
As festas dos clubes do laço e o Circuito de Laço Comprido em Mato Grosso do Sul
}

\author{
The rope club parties and Long Bow Circuit in Mato Grosso do Sul \\ Las fiestas de los clubes del lazo y el Circuito de Lazo Largo en Mato Grosso do Sul \\ Lilian da Silva Paiva ${ }^{1}$ \\ Gilberto Luiz Alves ${ }^{1}$
}

Recebido em 08/04/2018; revisado e aprovado em 11/05/2018; aceito em 11/05/2018

DOI: http://dx.doi.org/10.20435/inter.v20i4.1926

\begin{abstract}
Resumo: Este artigo tem por objeto o Circuito de Laço Comprido (CLC), competição realizada em Campo Grande e derivada das festas sul-mato-grossenses de clubes do laço. Objetiva descrever historicamente as festas de clubes do laço até a criação do CLC. O referencial teórico é construído sobre estudos de Queiróz e Sodré. Os dados empíricos decorrem de entrevistas semiestruturadas, visitas in loco e fontes secundárias A conclusão é a de que o CLC reflete as transformações tecnológicas correntes na pecuária e supera as festas dos clubes do laço.
\end{abstract}

Palavras-chave: desenvolvimento regional; pecuária; Campo Grande.

Abstract: This article has the Long Bow Circuit (CLC) as a aim, a competition realized in Campo Grande and derivative from Mato Grosso do Sul rope club parties. The objective, as well, to describe historically the rope club parties until the creation of CLC. The theoretical sources is built about on Queiróz and Sodré studies. The empirical data is obtained from semi-structured interviews, visits in loco and secondary sources. The conclusion is that CLC reflects the current technological development in livestock and overcomes the rope club parties.

Keywords: regional development; livestock; Campo Grande.

Resumen: Este artículo tiene por objeto el Circuito de Lazo largo (CLC), competición realizada en Campo Grande y derivada de las fiestas sul-mato-grossenses de clubes del lazo. Objetivo describir históricamente las fiestas de clubes del lazo hasta la creación del CLC. El referencial teórico fue construido sobre estudios de Queiróz y Sodré. Los datos empíricos se desarrollaron de entrevistas semiestructuradas, visitas in loco y fuentes secundarias. La conclusión es que el CLC refleja las transformaciones tecnológicas corrientes en la ganadería y supera las fiestas de clubes del lazo.

Palabras claves: desarrollo regional; ganadería; Campo Grande.

\section{INTRODUÇÃo}

Este artigo tem por objeto o Circuito de Laço Comprido (CLC), entidade que realiza competições em sede própria, denominada Parque do Peão, localizada na rodovia MS 010, Km 2, aproximadamente a $15 \mathrm{~km}$ do centro de Campo Grande, Mato Grosso do Sul. O objetivo geral é o de analisar historicamente as festas de clubes do laço, que estão na sua origem, bem como a do próprio CLC. O objetivo específico, dentro dessa intenção, visa apreender as mudanças nas funções dessas festas enquanto expressões das próprias mudanças sociais.

O Circuito do Laço Comprido é uma competição derivada das festas de clubes do laço que vinham acontecendo no sul de Mato Grosso desde meados de 1972. Com algumas adaptações às regras previamente existentes, desde 2010 o CLC passou a realizar competições todos os meses. A partir de 2012, essas competições passaram a ser realizadas em sede própria, o Parque do Peão, que dispõe de 100 hectares de área e estrutura construída especialmente para atender suas finalidades. Os encontros mensais envolvem a participação de cerca de 350 laçadores,

\footnotetext{
${ }^{1}$ Universidade Anhanguera-Uniderp, Campo Grande, Mato Grosso do Sul, Brasil.
} 
visitantes, comerciantes e fornecedores, movimentando a economia, especialmente no setor da agropecuária.

O CLC está estreitamente ligado a um dos fundamentos da economia regional: a pecuária. Foi ela que lastreou a ocupação inicial do espaço sul-mato-grossense. Conforme Sodré (1990), os primeiros rebanhos de gado bovino adentraram o sul do antigo Mato Grosso em fins do século XVIII, vindos do Sudeste do país e observando um deslocamento que atingiu toda a região Centro-Sul. Os primeiros a chegar vieram de Minas Gerais, ligados diretamente à cultura pastoril. Estavam em busca de terras férteis e pastagens propícias à criação do gado. Nos campos de vacaria, encontraram um vasto território apto à implantação de seus empreendimentos.

Esselin (2011) afirma que os rebanhos, além de se reproduzirem facilmente, já estavam dispersos pelo pantanal. "Os campos dos pantanais [...] estavam, no fim do século XVII, abrigando grandes manadas de bovinos e equinos que se multiplicavam muito rapidamente, aproveitando-se das boas condições ambientais" (ESSELIN, 2011, p. 18). Segundo o autor, o Paraguai estaria na origem dos primeiros rebanhos da região. Figueiredo (1994) data por volta de 1569 a chegada dos primeiros rebanhos ao Brasil e reafirma que as primeiras matrizes do sul de Mato Grosso teriam vindo do Paraguai, partindo de Assunção.

Uma pesquisa realizada sobre a cidade de Campo Grande reconhece a importância da pecuária desde os primórdios de sua fundação. Local privilegiado, assentado no centro dos campos do sul de Mato Grosso, Campo Grande cresceu ao incorporar-se ao comércio de gado. Seu desenvolvimento se intensificou com a ligação ferroviária e, depois, por meio de estrada de terra, ao Estado de São Paulo, região que concentrava a riqueza no Brasil, sob o impulso da economia do café, e era grande consumidora de gado bovino (GARDIN, 1999).

Deve-se salientar que o elemento determinante nesse processo foi a reprodução do capital. Foi o capital que deu direção à economia regional e definiu suas estratégias (ALVES, 2003). Atendendo à intensificação do consumo de carne no Estado de São Paulo, foram incrementados a produção e o comércio de gado no sul de Mato Grosso. Ampliando-se por todo o território, a pecuária foi disseminando fazendas de criação de gado que forneciam ao mercado produtos como a carne e o couro.

Da pecuária também nasceram festas como os rodeios e organizações como os clubes do laço. Por serem pouco estudadas essas manifestações, o objeto da investigação proposto centrou-se no Circuito de Laço Comprido - CLC, derivado das festas dos clubes do laço. Acentue-se que se trata de objeto inédito.

\section{REFERENCIAL TEÓRICO E METODOLOGIA}

O referencial teórico foi buscado em fontes que elucidam duas questões. A primeira, relativa estritamente ao objeto, teve como referência os estudos de Queiróz (1976). Analista das práticas culturais denominadas no âmbito do senso comum, quase sempre, como festas populares, ela afirma a necessidade de captação das funções sociais dessas práticas para captar sua historicidade. Essa busca deve ocorrer no âmbito das transformações que operam sobre a sociedade como um todo, pois elas são determinantes das funções sociais de suas partes. Nada é estático. Portanto apreender o movimento que está na base das mudanças das práticas culturais exige elucidar, por meio de mediações, como elas estão associadas às próprias mudanças sociais.

Daí decorre a segunda questão. Como as práticas culturais, a exemplo dos rodeios e das 
festas do peão, só se tornam inteligíveis quando referidas à sociedade, impôs-se o estudo da economia regional. A ocupação de Mato Grosso foi lastreada, desde o início do século XIX, na pecuária. As brincadeiras entre os peões e outros encontros festivos sempre estiveram associados à hegemonia exercida pela pecuária. Para compreender a implantação e a expansão da pecuária no sul de Mato Grosso, a base teórica essencial foi buscada em Sodré (1990), autor de um ensaio clássico sobre a grande propriedade pastoril no Centro-Oeste.

Para a obtenção de informações empíricas necessárias à análise, foram realizadas oito entrevistas semiestruturadas com fundadores ou familiares e componentes das Diretorias do primeiro clube de laço da região, localizado no município de Bela Vista. Foram entrevistados, igualmente, associados e laçadores de outros clubes, o idealizador do CLC e profissionais que atuam no mercado do cavalo. As entrevistas, previamente agendadas, ocorreram nas residências ou escritórios dos informantes. Um único caso demandou a obtenção de informações por meio eletrônico. Cada entrevistado foi estimulado a: a) dar sua versão sobre a história dessas festas; b) contar sua participação pessoal na realização de eventos festivos e c) expor sua interpretação sobre a crise das festas do peão e a emergência e solidificação do CLC.

Ainda para levantar dados foram realizadas sete visitas in loco à sede do CLC. Por meio de observação sistemática, foram colhidas informações acerca da infraestrutura do local do evento e do comportamento dos participantes. Depoimentos informais colhidos em situação de trabaIho também foram instrumentos explorados. Documentos, como o Estatuto do CLC e atas do Clube do Laço Bela Vista, além de periódicos impressos, foram igualmente consultados. Foram utilizadas, ainda, fontes secundárias que tratam, direta ou indiretamente, do desenvolvimento da pecuária no sul de Mato Grosso (FIGUEIREDO, 1994; GARDIN, 1999; NOGUEIRA, 2002; ALVES, 2004; BANDUCCI JR, 2007; ESSELIN, 2011; MORETTINI, 2012; SOUZA, 2012; RIBEIRO, 2015).

\section{RESULTADOS E DISCUSSÃO}

A pecuária em Mato Grosso do Sul já foi tratada por diversos estudiosos, sobretudo da área de História. Sodré (1990), por exemplo, escreveu um ensaio sobre a pecuária no Centro-Oeste, no qual discute a grande propriedade pastoril, sua expansão e o vaqueiro como sua figura central. O autor fala sobre a rusticidade dessa atividade econômica e da pobreza material dos criadores nos seus primórdios. A falta de recursos se expressou, quando da instalação das fazendas, nas precárias edificações de suas sedes, construídas exclusivamente com recursos locais.

Desde a constituição dos primeiros rebanhos, os proprietários e seus peões realizavam o trabalho no campo, ainda aberto, sem os mangueiros - ou mangas ou, ainda, mangueiras -, currais onde se recolhe o gado para captura, marcação, vacinação e outras atividades demandadas pela pecuária. O laço sempre foi instrumento fundamental dos trabalhadores no campo (PAIVA, 2008).

Quando certas tarefas anuais avultavam, os vizinhos se reuniam em mutirão para solidarizar-se uns com os outros. Eram oportunidades para a realização de vacinação do rebanho, castração (retirada dos testículos dos machos para engorda), marcação a ferro (com a marca em brasa do respectivo proprietário). Também eram realizadas atividades rotineiras no campo, como a apartação, o desmame de bezerros, a separação de gado, entre outras. Todas essas atividades sempre fizeram parte do cotidiano nas fazendas de criação de gado (MORETTINI, 2012). Elas constituíam, em grande parte, a lida, ou seja, o trabalho realizado no âmbito da pecuária (SOUZA, 2012). Ao 
final da lida, peões e proprietários se reuniam, brincavam e entretinham-se com as disputas de laçadas, com a música, a dança e churrasco. Aos ajudantes e convidados era oferecido um almoço, seguido de baile. Dessa forma, o congraçamento se estreitava e o proprietário exprimia seu agradecimento (PAIVA, 2008).

A rusticidade da pecuária fazia uso limitado de tecnologias. O laço, recurso central para o trabalho de campo, também disputava lugar privilegiado nas brincadeiras e competições que envolviam laçadas. Mas as inovações possíveis foram se impondo, como a implantação dos mangueiros e o cercamento das fazendas. Dessa forma, as atividades dos peões no campo foram simplificadas. É o que evidencia um estudo relacionado ao emprego de tecnologias nas fazendas de criação de gado do Pantanal da Nhecolândia:

[...] Apesar de reconhecer as habilidades singulares dos "camaradas" de antigamente, exímios cavaleiros e laçadores [...], José de Barros Netto reconhece, também, que o "progresso" e a "civilização" criaram maiores facilidades ao manejo do gado. A prática do cercamento das fazendas amansou o gado e as novas tecnologias simplificaram o exercício de outras atividades. (ALVES, 2004, p. 48).

O laço, instrumento de trabalho central nas lidas da pecuária, pode ser definido como "corda trançada com quatro tentos finos, comprida, com uma argola na ponta, usada para laçar animais, no campo ou no curral" (NOGUEIRA, 2002, p. 148). De início, era confeccionado pelos próprios peões, mas, com a capitalização da pecuária, hoje são adquiridos em casas comerciais especializadas dos centros urbanos.

A lida com o gado nas fazendas foi determinante para estimular as brincadeiras surgidas entre peões. A partir delas se fixaram algumas práticas culturais que se tornaram fontes permanentes de entretenimento e de congraçamento entre os participantes. Os rodeios nas fazendas e as competições entre os peões motivaram o surgimento das festas nos clubes do laço, desde então realizadas nas cidades.

Quando do surgimento das primeiras fazendas no sul de Mato Grosso o trabalho dos peões era mais complexo, pois envolvia diversas tarefas. A maior parte de suas vidas se concentrava no meio rural. Os proprietários compartilhavam tarefas similares, costumes, pensamentos e raramente abandonavam o campo (BANDUCCI JR, 2007).

As mudanças das relações sociais e seus reflexos, como as novas leis trabalhistas, exigiram ajustes às determinações do mercado e instauração de práticas que dificultaram a permanência dos trabalhadores no campo. Em entrevista, Wanderley Oliveira Coelho (2017) relatou sua experiência. Nascido em fazenda do interior de Mato Grosso do Sul, passou pelas transformações do mundo do trabalho no meio rural. Foi peão, capataz e, no mesmo período, laçador nas festas dos clubes do laço. Representou os clubes Dois Irmão do Buriti, no município homônimo, e Coração Pantaneiro, no município de Miranda. Hoje, Coelho é administrador rural e cuida de 5 fazendas para um empresário de São Paulo. Ele reconhece que as antigas relações de trabalho, em decorrência principalmente da introdução da tecnologia e das leis trabalhistas no campo, foram dissolvidas. Como consequência, foram eliminados os vínculos que aproximavam os trabalhadores.

"A relação de trabalho mudou muito de uns 15 anos pra cá e está mudando, e nós temos que acompanhar senão nós vamos ficar pra trás. Hoje a fazenda é uma empresa" (COELHO, 2017). Essa situação é geral. Ocorre de norte a sul de Mato Grosso do Sul e está associada ao sistema capitalista de produção, que dissolveu as antigas relações sociais nos campos de pecuária para 
obedecer à racionalidade da economia empresarial (KRISIS, 1999).

Ao contrário do que ocorria no passado, hoje os filhos de peões já não participam da lida no campo com os pais. Com isso, deixaram de ter apego ao campo e ao cotidiano da fazenda. Conforme o relato do entrevistado:

O filho do capataz [...] chegava da escola e já ia para o campo à tarde [...] e já participava e aprendia, hoje é proibido, na verdade, hoje na empresa em que eu trabalho o filho do funcionário não pode sair no campo, nem ir no trator [...] é proibido. (COELHO, 2017).

Houve, necessariamente, expropriação do saber do trabalhador rural a partir da introdução de novas tecnologias. E houve, também, diminuição do número de trabalhadores para a realização das atividades simplificadas da pecuária.

Outro aspecto importante relacionado às mudanças no meio rural refere-se ao salário pago aos peões. No passado ele era negociado de várias maneiras. Algumas vezes, parte do pagamento correspondia a certa quantidade de cabeças de gado. O patrão também poderia disponibilizar pastagens para o pequeno plantel do(s) empregado(s). Dessa forma, o peão acabava se vinculando mais estreitamente ao meio em que vivia. No local passava anos com a família. Os filhos, geralmente, aprendiam o ofício dos pais e continuavam exercendo a profissão nas fazendas e vivendo dos rendimentos do trabalho no campo. Sucessivas gerações reproduziam o viver e o fazer das pregressas. O salário em espécie não era comum, pois a vida ocorria nos limites das fazendas, distante dos centros urbanos e de seus equipamentos como as agências bancárias. Essa situação gerava maior controle dos patrões. A relação de poder pendia para os proprietários e tornava os empregados inteiramente submissos (RIBEIRO, 2015).

O salário, nos dias atuais, é imposto por lei. Contribui, assim, para a flutuação dos trabalhadores por diversas propriedades. Perdem, dessa forma, o vínculo com o lugar. O salário, nivelado o mais estritamente possível aos meios de subsistência, não permite que o trabalhador rural adquira animais nem que disponha de terras para criá-los. No plano social, os peões nas fazendas perderam vínculos de coesão com os patrões e com os demais trabalhadores. As relações entre eles, antes pautadas pela camaradagem, formavam um círculo que gerava fidelidade e amizade, que culminava com relações de compadrio. As transformações econômicas no campo, decorrentes da modernização tecnológica, foram acompanhadas de intensa rotatividade dos trabalhadores. Como afirma Ribeiro (2015, p. 168), "No interior da estrutura capitalista, a demasiada rotatividade de trabalhadores gera cidadãos sem referências, sem o sentimento de pertença com o lugar".

Essa contextualização permite que se volte às festas nos clubes do laço. As brincadeiras e competições entre peões, iniciadas no interior das fazendas de gado, foram direcionadas para as festas dos clubes de laço, sediadas numa cidade próxima. Ganharam maior amplitude. É o que reconhece João Augusto Mascarenhas (2012), um dos componentes da primeira equipe de laço comprido de Mato Grosso do Sul. As festas, segundo ele, surgiram a partir da lida com o gado nas fazendas, consolidando a coesão dos vizinhos e para culminar atividades como a marcação, a cura e a vacinação do rebanho. Nesses mutirões, as festas representavam o momento de descontração, após a conclusão dos serviços. Os clubes do laço foram sucedâneos dessas festas e ampliaram o seu âmbito ao permitirem o congraçamento de diversos proprietários e peões de uma mesma região.

Foi num dia de trabalho no campo que o entrevistado foi convidado para laçar em um 
clube do laço.

Sabe como o Olympio (Cardinal) descobriu que eu laçava? Vou te contar: [...] lá no Pantanal, na beira do Rio Paraguai. O Olympio comprou uma boiada minha [...] e fomos apartar (separar) os bois, daí saiu um boi no refugo, aí eu montei a cavalo, ele também e fui laçar o boi [...], joguei o laço por cima dos outros bois e peguei ele nos dois chifres. Daí o Olympio falou: João você vai laçar com a gente lá em Bela Vista. (MASCARENHAS, 2012).

Esse fato se deu em meados de 1968, antes, portanto, da criação oficial do primeiro clube do laço, ocorrida por volta de 1972, no município de Bela Vista. Desde então se iniciaram as primeiras festas de clubes do laço.

Enquanto festas, elas passaram a expressar as relações sociais dominantes. Envolvendo comemoração, dança, comida, canto, diversão, companheirismo, desde o início elas promoveram a interação, comunicação, além da confraternização e coesão entre os participantes.

As festas de clubes do laço compreendiam disputas de laçadas entre várias equipes compostas por cinco laçadores montados a cavalo. Perseguiam eles o objetivo de laçar corretamente uma rês numa pista. Frise-se, mais uma vez, que também faziam parte dessas festas os bailes, entretenimento e confraternização entre as famílias dos participantes. Mesmo originárias de municípios distintos, no dia do encontro nos clubes do laço, as pessoas se juntavam para celebrar, festejar e confraternizar.

As competições eram realizadas pela utilização, como se deduz, do laço. Contudo esse instrumento já não era mais fabricado artesanalmente. Incorporando maior grau de tecnologia, ele passava a dar maior versatilidade e mobilidade ao laçador no momento das disputas. Nos clubes do laço os participantes denominaram laço comprido a longa corda de couro também usada pelos peões na lida das fazendas. Todavia, hoje, o laço utilizado nas fazendas não é o mesmo usado nas competições. O primeiro deve ser mais grosso e rústico para laçar os animais em campo aberto sem o risco de arrebentar. Já o laço esportivo deve ser mais fino e envolver uma espécie de chumbo na parte interna para ganhar maleabilidade e favorecer as laçadas. Não só os laços mudaram. Também os laçadores já não são os domadores e treinadores dos seus cavalos. Tampouco possuem habilidades para produzir laços, como antigamente.

Sobre as festas nos clubes do laço, Edson Medeiros de Moraes (2016) relatou que começou a laçar em uma fazenda de Bela Vista, propriedade de Olimpyo Cardinal, junto com os amigos Luiz Gonzaga de Araújo e José Marçolla. Surgiu entre eles a ideia de fundar um clube do laço para envolver mais simpatizantes desse esporte. Reuniram 25 "companheiros" para comprar uma chácara com a finalidade de sediar o primeiro clube do laço do sul de Mato Grosso. Participavam patrões e peões. O entrevistado não soube precisar a data desse acontecimento.

Zélia Rocha Marçolla (2016), esposa de um dos fundadores do Clube do Laço Bela Vista, afirmou que o principal motivo para a sua criação se prendeu à necessidade de aperfeiçoamento e ampliação de uma modalidade esportiva já cultivada nas fazendas, para propiciar diversão, sem outros interesses. Portanto a função das festas no momento de fundação desse primeiro clube do laço estava voltada especificamente ao entretenimento, à diversão e à confraternização entre os familiares e amigos dos laçadores. Queiroz (1976) reforça esse fato ao afirmar que tais festas sempre foram recursos para assegurar coesão e solidariedade entre os participantes (QUEIROZ, 1976).

A partir do Clube do Laço Bela Vista, outros foram fundados nos mesmos moldes, especialmente na região de fronteira com o Paraguai. Surgiram novas unidades, por exemplo, nos municípios de Ponta Porã, Guia Lopes, Jardim, Dourados, Antônio João e Aral Moreira.

Para os clubes do laço foram transplantadas as relações sociais vigentes entre patrões e 
empregados. A participação do empregado se resumiu à condição de peão, enquanto os patrões assumiram as funções de direção. Grande parte dos eleitos para dirigir os clubes no laço no Estado sempre foi formada por pecuaristas, os detentores do capital.

Os valores e padrões culturais, os modos de viver e pensar, as condições materiais e intelectuais de vida e trabalho têm muito a ver com as condições de organização do poder político e econômico, em todos os lugares. Na fábrica, na fazenda, escritório, escola, igreja, casa, em todos os lugares, as condições sociais, políticas e econômicas de viver e trabalhar compreendem inclusive, necessariamente, a cultura. (IANNI, 1996, p. 155).

Ainda hoje os dirigentes dos clubes do laço são os pecuaristas que possuem propriedades nos municípios de sua região de influência. Essa é uma "regra" incondicional. Os pecuaristas são também patrões nas festas em referência.

Luiz Gonzaga de Araújo (2012), outro membro da primeira Diretoria do Clube do Laço Bela Vista e componente da pioneira equipe de laço do Estado, relatou que as regras dos clubes do laço em Mato Grosso do Sul foram incorporadas a partir de estatutos já utilizados por entidades similares da região Sul do país. O acesso foi possibilitado por meio de relações de amizade.

As festas dos clubes do laço envolvem diversos componentes característicos, desde a abertura oficial, a aferição e marcação dos laços, a comida regional, a música e a dança, além do baile que ocorre em paralelo às disputas das laçadas. Denominado caarapé ou baile pequeno, perdura até o encerramento, quando acontece a entrega dos troféus aos campeões.

Desde 2002 as festas foram encurtadas. Resumiram-se aos sábados e domingos, em decorrência dos gastos com transporte dos participantes e seus respectivos cavalos, com exames obrigatórios dos animais, com inscrição dos laçadores, com alimentação e hospedagem (PAIVA, 2008).

Desde a criação do Clube do Laço Bela Vista e dos que o secundaram na fronteira, outros se difundiram alargando seu âmbito para todo o atual Estado de Mato Grosso do Sul. Os fundadores e os novos membros começaram a atentar para a necessidade de maior organização das festas e das competições. Embora alguns estatutos de clubes já tivessem sido reformulados, a demanda era por algo maior.

A Federação de Clubes do Laço de Mato Grosso do Sul, criada em 14 de abril de 1984, estimulou reformulações que se faziam necessárias. Uma delas foi a "divisão" dos clubes em dois grupos, o Grupo A e o Grupo B, ocorrida no ano de 1992 (PAIVA, 2008). O grupo A passou a compreender os clubes localizados nos municípios de Nioaque, Jardim, Guia Lopes da Laguna, Caracol, Bela Vista, Antônio João, Dourados, Ponta Porã, Laguna Carapã, Aral Moreira, Amambai, Coronel Sapucaia, Paranhos, Tacuru e Sete Quedas. Os componentes do Grupo B reuniam clubes do laço dos municípios de Campo Grande, Aquidauana, São Gabriel do Oeste, Rio Brilhante, Bonito, Camapuã, Sidrolândia, Corumbá, Rio Verde de Mato Grosso, Anastácio, Bandeirantes, Jaraguari, Dois Irmãos do Buriti, Ribas do Rio Pardo, Maracaju, Corguinho, Miranda, Nova Alvorada do Sul e Coxim (FEDERAÇÃO DE CLUBES DO LAÇO DE MATO GROSSO DO SUL [FCLMS], 2015). A proximidade geográfica foi o critério de agrupamento.

Com a expansão dos clubes do laço, houve a necessidade de readequação dos grupos, daí a criação do Grupo C em 2003. Com a redistribuição realizada, os clubes do grupo A estão localizados na região Sudoeste do Estado, os de grupo B no Centro e os do grupo C na região Sul, fronteira com o Paraguai.

As festas desses clubes ficaram conhecidas. Atraíram, progressivamente, maior público 
gerando maior receita. Elas evidenciaram potencial para transformar-se num grande negócio. Além do aumento de público visitante, a exposição de novas tecnologias e o estímulo à inovação da pecuária passaram a ter lugar nessas festas. Os cavalos, que nos primórdios eram os mesmos utilizados nas fazendas e transportados pelos proprietários quando das festas, passaram a ser selecionados exclusivamente para as competições. Foi o que relatou o entrevistado Virlian Hildebrand Lara (2017).

O incremento às festas e o seu caráter cada vez mais complexo culminaram com a implantação do Circuito do Laço Comprido em Campo Grande. As festas ganharam maior amplitude. O processo de especialização se aprofundou, manifestando-se na profissionalização dos participantes. Os cavalos passaram a ser produzidos especificamente para as competições. Os laçadores também se profissionalizam.

As competições do CLC têm início em janeiro e acontecem durante todos os meses do ano até dezembro. Suas atividades se organizam em torno das disputas de laçadas entre as equipes. Enquanto adaptação das festas de clubes do laço, já recorrentes no Estado, o Circuito aderiu a algumas inovações que the emprestam singularidade.

Idealizado por um jovem laçador, Abeldes Silva Rocha Júnior, o Circuito de Laço Comprido teve início no ano de 2010. Na ocasião, o local de realização do evento foi o Parque de Exposições Laucídio Coelho, em Campo Grande. Em entrevista, Rocha Júnior (2017) afirmou que foi motivado a criá-lo nessa cidade pelo seu maior potencial de aglutinação de participantes. Foi apoiado por amigos, com destaque para os irmãos Eduardo Arcas e Juliano Arcas, empresários. A primeira competição do CLC aconteceu em 22 de janeiro de 2010.

Ainda em 2011 o CLC foi realizado no Parque de Exposições, quando houve embargo às suas atividades. Os organizadores foram informados de que suas competições não poderiam mais realizar-se no local. A decisão da diretoria foi a de adquirir uma área propícia às necessidades do circuito. Foi criado, para tanto, um condomínio. Nele, imediatamente, começaram a ser edificadas as estruturas necessárias para que a entidade promovesse suas competições. Criado o Parque do Peão, no dia 13 de maio de 2012 aconteceu a primeira etapa do CLC em sede própria.

O próprio CLC deve ser entendido como instrumento de inovação. Surgiu com o intuito de aprimorar a competição, de melhorar as condições oferecidas aos laçadores nas provas e promover cada vez mais o laço comprido. Se as inovações tecnológicas realizaram mudanças nas relações de trabalho no campo, determinaram também o êxodo dos antigos peões e a fragilização das bases de organização dos clubes do laço. O CLC representou um ajustamento à nova situação e criou condições objetivas para que antigos e novos peões, agora profissionalizados e não mais trabalhadores no campo, pudessem exercer a atividade de laçar, que exige perícia e promete prêmios expressivos em dinheiro e mercadorias. Logo, sob esse aspecto, o CLC distancia-se muito das festas dos clubes do laço, onde os vínculos entre os participantes eram marcados pela solidariedade, pelo congraçamento e pela competição desinteressada.

A maioria das equipes competidoras no CLC, portanto, é composta por laçadores profissionais. Já não são frequentes as equipes formadas por amigos, peões e patrões. Predominam os laçadores profissionais, que sobrevivem da prática do laço comprido. É cada vez mais rara a presença de membros não profissionais numa mesma equipe. O que se nota de substantivo, no CLC, é que foram dissolvidas as relações baseadas na amizade, no congraçamento, na busca do entretenimento (QUEIRÓZ, 1976), para a emergência de relações estritamente profissionais.

Os participantes se movem pela competição e pela busca da premiação. Daí a preocu- 
pação com o aprimoramento da performance. Daí, igualmente, o surgimento dos centros de treinamento e doma de animais, voltados com exclusividade para a participação no CLC. Os cavalos competidores já não são os das fazendas, permanecendo todo o tempo nos centros de treinamento alojados em cocheiras.

Por trás dessas mudanças, ocorrem demandas por especializações profissionais e geração de empregos em áreas como tratadores, médicos veterinários, casqueadores, treinadores, criadores de animais, fornecedores de medicamentos e de alimentos. Um exemplo ilustrativo é o do médico veterinário Márcio Podolan, paranaense que chegou a Campo Grande em 2013. Atualmente trabalha na área de odontoplastia e atende uma média de 300 animais ao ano. Em entrevista afirmou que a demanda pelo tipo de serviço que oferece tem aumentado, e a tendência é de incremento. Concluiu deixando claro que a "maior parte do meu trabalho é voltada aos cavalos de laço comprido; é um mercadão. O país inteiro está laçando no laço comprido" (PODOLAN, 2017).

Sobre a natureza das competições do CLC, afirme-se que a entidade estabeleceu regras claras. Algumas já faziam parte das festas dos clubes do laço e foram adaptadas, de forma a tornar as competições mais atraente aos participantes. Tais regras integram o Estatuto do CLC, em vigor desde a sua primeira edição. Segundo elas, a equipe de competição é formada por 5 laçadores. Posicionados dentro da pista, cada componente deve passar pelo toco de rodilhas - instrumento de madeira com $45 \mathrm{~cm}$ de diâmetro -, no qual são medidas as 4 rodilhas do laço. Elas devem caber no referido medidor. Para o caso dos laçadores adultos, o laço deve estar armado com 8 metros de comprimento.

Os laçadores devem se posicionar, um de cada vez, ao lado do brete, corredor estreito onde cabe apenas um animal. Dotado de um portão de saída, o operador o abre somente quando a rês é liberada para percorrer a pista e ser laçada. Sucessivamente, os demais membros da equipe se posicionam próximos ao brete de saída e realizam o mesmo procedimento até que o último componente conclua a sua laçada. O primeiro laçador é chamado Capitão, e o último é o Fecha-Rosca ou Presilha. O animal deve ser laçado até uma distância de 100 metros do brete de saída. O chapéu do laçador não pode cair de sua cabeça durante a operação. Caso isso ocorra, o competidor perde a sua armada ou laçada, mesmo que tenha sido positiva. A armada positiva é aquela em que o laço envolve os chifres ou orelhas do animal. Caso a armada coloque o laço no pescoço da rês é considerada negativa. Um juiz, denominado bandeirinha, verifica a posição do laço no final da pista, junto ao brete de chegada. Com uma bandeira branca sinaliza a armada positiva e uma bandeira vermelha a armada negativa.

Após o término das laçadas de todos os integrantes de uma equipe, outra entra na pista e dá continuidade à competição. Ao final, somam-se os pontos e vence a competição a equipe que obtiver maior pontuação na contagem geral. O circuito é disputado por até 85 equipes e, dependendo do mês, por uma média de 350 laçadores. Existe uma lista de equipes aguardando vaga para laçar no CLC.

No circuito, as normas quanto à vestimenta não são rígidas. É permitido o uso de qualquer tipo de roupa, desde que seja calça comprida, camisa e chapéu. Também são permitidas a bombacha gaúcha e a camisa do tipo polo. Se preferirem, os laçadores podem utilizar a sela de origem americana ao invés do arreio, utilizado pelos peões nas fazendas. As botas, chapéus e demais acessórios do vestuário norte-americano são cada vez mais frequentes entre os laçadores.

Uma inovação relevante do Circuito é constatada na premiação aos campeões. Nos clubes 
do laço filiados à Federação, os prêmios sempre foram troféus, de valor apenas simbólico para os laçadores. Já no CLC, os prêmios principais são conferidos em dinheiro ou envolvem mercadorias de alto valor como motocicletas e automóveis. O prêmio simbólico no Circuito é uma medalha. Por meio de observação e de depoimentos informais, verificou-se que o interesse maior dos laçadores se prende às premiações em valores materiais. Elas contribuem para a reprodução da existência dos competidores e para que recuperem os investimentos exigidos pela participação nas competições.

Nesse quadro, os interesses pessoais ganharam centralidade e a competição pelos prêmios se acirrou. A disputa entre os competidores não é mais aquela que se dava nas confraternizações entre amigos nos clubes do laço. No CLC, cada etapa oferece premiação de até $\mathrm{R} \$ 25.000,00$. A cada mês os laçadores "brigam" para conquistar a premiação pertinente a cada categoria ${ }^{2}$. A competição diminuiu o espírito de confraternização e até a amizade sucumbiu.

Em cada edição são utilizados, em média, 1.000 animais fornecidos por proprietários que investem em produção voltada exclusivamente à competição. Essa é outra novidade instaurada pelo CLC. Nas festas regionais de clubes do laço, os sócios ainda emprestam o gado, que, muitas vezes, é conduzido a pé das fazendas até os clubes, de acordo com os recursos de cada proprietário. Foi o que relatou Lara (2017) em entrevista. Essas festas ainda estimulam a colaboração e a solidariedade entre famílias de proprietários e de peões no âmbito de suas áreas de influência regional, demonstração de que a função social de coesão perdura (QUEIROZ, 1976).

Nos clubes do laço, há uma comissão julgadora e locutores que fazem a rotina fluir e promovem o cumprimento das regras da competição. Eles integram o grupo de amigos que envolve desde os laçadores até os sócios. No CLC quem cumpre esses papéis são profissionais contratados.

Acentue-se, por fim, que há uma tendência de aumento do número de circuitos em Mato Grosso do Sul. Os clubes do laço se fragilizam, pois passam a enfrentar uma competição em condições desfavoráveis. Na esteira do CLC de Campo Grande, surgiram o Circuito Nabileque de Laço Comprido, em Bonito, o Circuito Miranda e Bodoquena, o Circuito Independente do Grupo A, em vários municípios do Estado, e mais dois em Campo Grande, o Circuito Morena de Laço Comprido e o Copa Acrissul de Laço Comprido. Como se observa, estão emergindo estruturas flexíveis que podem se situar numa única cidade ou, ao mesmo tempo, envolver a coparticipação de diversos municípios sul-mato-grossenses.

\section{CONSIDERAÇÕES FINAIS}

Sintetizando, o Circuito de Laço Comprido derivou das festas de clubes do laço. Mesmo mantendo muitas de suas regras, a competição passou a dar destaque à disputa pelos prêmios em dinheiro e objetos de elevado valor. Os competidores do CLC não são peões, necessariamente. São profissionais do laço, motivados principalmente pela premiação. A função de confraternização e solidariedade com amigos, tão evidente nas festas dos clubes de laço, deixou de ser central no Circuito.

Os trabalhadores se especializaram no âmbito do CLC. Hoje são, tão somente, laçadores. Os cavalos de competição também passaram por especialização. Já não são os cavalos de lidas

\footnotetext{
2 São as seguintes as categorias de laçadores, segundo o Estatuto do CLC: Laçador Mirim, Laçador Bandeira, Laçador Universitário, Veterano, Amazonas Mirim, Amazonas Adulta, Laçador Letrado, Pai/Mãe e Filho(a), Capitão, Trio, Fecha Rosca, Individual, Patrão Proprietário, Cavalo Registrado e Cavalo Registrado Amador.
} 
nas fazendas. São mercadorias especializadas, produzidas por um tipo de criador especializado, visando atender à finalidade exclusiva de competir no circuito.

De fato, a transição das festas dos clubes de laço para o CLC denota profunda mudança nas relações sociais no campo. Decorrentes da introdução de novas tecnologias e da legislação trabalhista, elas diluíram os laços de solidariedade entre patrões e empregados e entre os próprios peões. Desapareceram os festivos mutirões, por exemplo, que aproximavam moradores de fazendas próximas, patrões e empregados, oportunidades que estimulavam a socialização, a solidariedade e o entretenimento. Hoje, o CLC é um espaço por onde circula uma gama imensa de profissionais especializados, inclusive os laçadores. Estes, basicamente movidos pela premiação material, veem os seus iguais como competidores e ameaça à obtenção do prêmio.

\section{AGRADECIMENTOS}

À Coordenação de Aperfeiçoamento de Pessoal de Nível Superior (CAPES), pela bolsa de estudos concedida.

\section{REFERÊNCIAS}

ALVES, G. L. Pantanal da Nhecolândia e modernização tecnológica: estudo das expectativas dos pecuaristas colhidas em suas memórias. Campo Grande: UFMS, 2004. 86p.

ALVES, G. L. O universal e o singular: em discussão a abordagem científica do regional. In: ALVES, G. L. Mato Grosso do Sul: o universal e o singular. Campo Grande: Editora Uniderp, 2003. p. 17-29.

ARAÚJO, L. G. Entrevista realizada pelos autores, em Campo Grande, Mato Grosso do Sul, em 3 de junho de 2012.

BANDUCCI JR, A. A natureza do pantaneiro: relações sociais e representações de mundo no "Pantanal da Nhecolândia". Campo Grande: UFMS, 2007. 224p.

COELHO, W. O. Entrevista realizada pelos autores, em Campo Grande, Mato Grosso do Sul, em 21 de setembro de 2017.

ESSELIN, P. M. A pecuária bovina no processo de ocupação e desenvolvimento econômico do pantanal sul-mato-grossense (1830-1910). Dourados: UFGD, 2011. 358p.

FEDERAÇÃO DE CLUBES DO LAÇO DE MATO GROSSO DO SUL (FCLMS). Estatuto. Campo Grande, 2015. Disponível em: http://www.federacaodelaco.com.br/estatuto/. Acesso em: 17 nov. 2017.

FIGUEIREDO, A. A propósito do boi. Cuiabá: UFMT, 1994. 226p.

GARDIN, C. Campo Grande: entre o sagrado e o profano. Campo Grande: Editora da UFMS, 1999.

IANNI, O. A ideia de Brasil moderno. São Paulo: Brasiliense, 1996. 200p.

KRISIS. Manifesto contra o trabalho. Tradução de Heinz Dieter Heidemam com a colaboração de Claudio Duarte. São Paulo: USP, 1999. 29p. (Cadernos do Labur, n. 2).

LARA, V. H. Entrevista realizada pelos autores, em Campo Grande, Mato Grosso do Sul, em 19 de janeiro de 2017.

MARÇOLLA, Z. R. Entrevista pelos autores, por meio eletrônico, em 26 de setembro de 2016. 
MASCARENHAS, J. A. Entrevista realizada pelos autores, em Bonito, Mato Grosso do Sul, em 8 de junho de 2012.

MORAES, E. M. Entrevista realizada pelos autores, em Campo Grande, Mato Grosso do Sul, em 25 de agosto de 2016.

MORETTINI, M. T. Expressões regionais: caderno de leitura. Campo Grande: UFMS, 2012. 140p.

NOGUEIRA, A. X. Pantanal: homem e cultura. Campo Grande: UFMS, 2002. 155p.

PAIVA, L. S. As festas de clubes do laço de Mato Grosso do Sul. 2008. 75f. Dissertação (Mestrado em Geografia) - Universidade Federal de Mato Grosso do Sul, Aquidauana, MS.

PODOLAN, Márcio. Entrevista realizada pelos autores, em Campo Grande, Mato Grosso do Sul, em 30 de janeiro de 2017.

QUEIROZ, M. I. P. O campesinato brasileiro: ensaios sobre civilização e grupos rústicos no Brasil. 2. ed. Petrópolis: Vozes, 1976. 242p.

RIBEIRO, M. A. Entre cheias e vazantes: a produção de geografias no Pantanal. Campo Grande: UFMS, 2015. 232p.

ROCHA JÚNIOR, A. Entrevista realizada pelos autores, em Campo Grande, Mato Grosso do Sul, em 30 de janeiro de 2017.

SODRÉ, N. W. Oeste: ensaio sobre a grande propriedade pastoril. São Paulo: Arquivo do Estado, 1990. 206p.

SOUZA, P. R. Pantanal de A a Z: vocabulário contextualizado aos pantaneiros da Nhecolândia, do MirandaAbobral e do rio Paraguai. Campo Grande: UFMS, 2012. 68p.

\section{Sobre os autores:}

Rafael Gonçalves Gumiero: Doutoranda em Meio Ambiente e desenvolvimento Regional pela Universidade Anhanguera-Uniderp, Campo Grande, MS. Bolsista/taxa CAPES. E-mail: lilian_stb7@hotmail.com, Orcid: http://orcid.org/0000-0002-4247-4672

Gilberto Luiz Alves: Doutor em Educação pela Universidade Estadual de Campinas. Professor pesquisador da Universidade Anhanguera-Uniderp e estuda os impactos culturais e ambientais decorrentes de propostas de desenvolvimento regional formuladas por órgãos governamentais, não governamentais e movimentos sociais. E-mail: gilbertoalves9@uol.com.br, Orcid: http://orcid.org/0000-0001-9672-1459 